\title{
Computing the Wiener index of graphs on triples
}

\section{GHORBANI}

\section{ABSTRACT.}

Let $S$ be a set of size $n \geq 8$ and $V$ be the set of all subsets of $S$ of size 3 . Three types of intersection graphs $G_{i}(n), i=0,1,2$, can be defined with the vertex set $V$ whose Wiener indices will be calculated in this paper.

\section{REFERENCES}

[1] Darafsheh, M. R., Computing the topological indices of some graphs, Acta Appl. Math., 110 (2010), 1225-1235

[2] Darafsheh, M. R., The Wiener, Szeged and PI index of the triangle graph, in Proceedings of the 5th Asian Mathematical Conference, Kuala Lumpur, Malaysia (Keong, L. S. and Kamarul, H., Eds.), 2009, Vol. I, 81-89

[3] Dobrynin, A. A., Entringer, R., and Gutman, I., Wiener index of trees: Theory and applications, Acta Appl. Math., 66 (2001), 211-249

[4] Dobrynin, A. A., Gutman, I., Klavzar, S. K., and Zigert, P., Wiener index of hexagonal systems, Acta Appl. Math., 72 (2002), $247-294$

[5] Gutman, I., Furtula, B., and Belic, J., Notes on the hyper-Wiener index, J. Serb. Chem. Soc., 68 (2003), 943-948

[6] Gutman, I., Yeh, Y. N., Lee, S. L., and Chen, J. C., Wiener number of dendrimers, MATCH Commun. Math. Comput. Chem., 30 (1994), 103-115

[7] Harary, F., Graph theory, Addison Wesley, Reading ,1968

[8] Hosoya, H., Topological index. A newly proposed quantity characterising the topological nature of structural isomer of saturated hydrocarbons, Bull. Chem. Soc. Jpn., 4 (1971), 2332-2339

[9] Mohammadyari, R. and Darafsheh, M. R., Topological indices of the double odd graph $2 O_{k}$, Creative Math. \& Inf., 20 (2011), 163-170

[10] Prabhakara, Rao, N. and Laxmi Prasanna, A., On the Wiener index of pentachains, Appl. Math. Sci., 2 (2008), 2443-2457

[11] Wiener, H., Strustural determination of paraffin boiling points, J. Am. Chem. Soc., 69 (1947), 17-20

Department of Mathematics AND TeChNology

MAZANDARAN UNIVERSITY OF SCIENCE

P.O. BOX 11111, BEHSHAHR, IRAN

E-mail address: m_ghorbani@iust.ac.ir 